Please do not remove this page

RMIT

UNIVERSITY

\title{
Miniature loop heat pipe with flat evaporator for cooling computer CPU
}

Singh, Randeep; Akbarzadeh, Aliakbar; Dixon, Christopher; Mochizuki, Mastaka; Riehl, Roger

https://researchrepository.rmit.edu.au/esploro/outputs/9921860569801341/filesAndLinks?institution=61 RMIT_INST\&index=null

Singh, R., Akbarzadeh, A., Dixon, C., Mochizuki, M., \& Riehl, R. (2007). Miniature loop heat pipe with flat evaporator for cooling computer CPU. IEEE Transactions on Components and Packaging Technologies, 30, 42-49. https://doi.org/10.1109/TCAPT.2007.892066

Published Version: https://doi.org/10.1109/TCAPT.2007.892066

Repository homepage: https://researchrepository.rmit.edu.au

(c) 2007 IEEE. Personal use of this material is permitted. However, permission to reprint/republish this material for advertising or promotional purposes or for creating new collective works for resale or redistribution to servers or lists, or to reuse any copyrighted component of this work in other works must be obtained from the IEEE.

Downloaded On 2023/04/27 00:07:05 +1000 


\title{
Miniature Loop Heat Pipe With Flat Evaporator for Cooling Computer CPU
}

\author{
Randeep Singh, Aliakbar Akbarzadeh, Chris Dixon, Mastaka Mochizuki, and Roger R. Riehl
}

\begin{abstract}
This paper presents an experimental investigation on a copper miniature loop heat pipe (mLHP) with a flat disk shaped evaporator, $30 \mathrm{~mm}$ in diameter and 10-mm thick, designed for thermal control of computer microprocessors. Tests were conducted with water as the heat transfer fluid. The device was capable of transferring a heat load of $70 \mathrm{~W}$ through a distance up to $150 \mathrm{~mm}$ using 2-mm diameter transport lines. For a range of power applied to the evaporator, the system demonstrated very reliable startup and was able to achieve steady state without any symptoms of wick dry-out. Unlike cylindrical evaporators, flat evaporators are easy to attach to the heat source without need of any cylinder-to-plane reducer material at the interface and thus offer very low thermal resistance to the heat acquisition process. In the horizontal configuration, under air cooling, the minimum value for the mLHP thermal resistance is $0.17{ }^{\circ} \mathrm{C} / \mathrm{W}$ with the corresponding evaporator thermal resistance of $0.06{ }^{\circ} \mathrm{C} / \mathrm{W}$. It is concluded from the outcomes of the current study that a mLHP with flat evaporator geometry can be effectively used for the thermal control of electronic equipment including notebooks with limited space and high heat flux chipsets. The results also confirm the superior heat transfer characteristics of the copper-water configuration in mLHPs.
\end{abstract}

Index Terms-CPU cooling, flat evaporator, miniature loop heat pipe (mLHP), thermal control.

\section{NOMENCLATURE}

$\begin{array}{ll}\mathrm{A} & \text { Area, } \mathrm{m}^{2} . \\ \mathrm{R} & \text { Thermal resistance, }{ }^{\circ} \mathrm{C} / \mathrm{W} . \\ \mathrm{T} & \text { Temperature, }{ }^{\circ} \mathrm{C}, \mathrm{K} \\ \bullet & \text { Heat load, } \mathrm{W} . \\ Q & \text { Heat transfer coefficient, } \mathrm{W} / \mathrm{m}^{2 \circ} \mathrm{C} . \\ \mathrm{h} & \text { Merit number, } \mathrm{W} / \mathrm{m}^{2} . \\ \mathrm{M} & \text { Latent heat of vaporization, } \mathrm{J} / \mathrm{Kg} .\end{array}$

\section{Greek Symbols}

$\begin{array}{ll}\sigma & \text { Surface tension } \mathrm{N} / \mathrm{m} . \\ \rho & \text { Density, } \mathrm{Kg} / \mathrm{m}^{3} . \\ \mu & \text { Viscosity, Pa.s. }\end{array}$

Manuscript received November 4, 2005; revised April 4, 2006. This work was recommended for publication by Associate Editor C. Patel upon evaluation of the reviewers' comments.

R. Singh, A. Akbarzadeh, and C. Dixon are with the Energy CARE Group, School of Aerospace, Mechanical and Manufacturing Engineering, Royal Melbourne Institute of Technology (RMIT) University, Victoria 3083, Australia (e-mail: randeep.singh@rmit.edu.au).

M. Mochizuki is with Fujikura, Ltd., Tokyo 135, Japan.

R. R. Riehl is with the Space Mechanics and Control Division, National Institute for Space Research-INPE, São José dos Campos 12227-010, Brazil.

Digital Object Identifier 10.1109/TCAPT.2007.892066

$\begin{array}{ll}\text { Subscripts } \\ a & \text { Ambient. } \\ c c & \text { Compensation chamber. } \\ c & \text { Condenser. } \\ e & \text { Evaporator. } \\ j & \text { Junction. } \\ h p & \text { Heat pipe. } \\ t & \text { Total. } \\ v & \text { Vapor. } \\ l & \text { Liquid. }\end{array}$

\section{INTRODUCTION}

$\mathbf{T}$ HE development of high-end and compact computers has resulted in a considerable rise in the power dissipation tendency of their microprocessors. At present, the waste heat released by the central processing Unit (CPU) of a desktop and server computer is 80 to $130 \mathrm{~W}$ and of notebook computer is 25 to $50 \mathrm{~W}$ [1]. In the latter case, the heating area of the chipset has become as small as $1-4 \mathrm{~cm}^{2}$. This problem is further complicated by both the limited available space and the restriction to maintain the chip surface temperature below $100{ }^{\circ} \mathrm{C}$. It is expected that conventional two-phase technologies [2] like heat pipes and vapor chambers will not be able to meet the futuristic thermal needs of the next generation notebooks. Other technologies like liquid cooling and thermoelectric coolers have good potential but still create major integration, reliability and cost issues. With the development in the two-phase heat transfer systems and porous media technology, loop heat pipes (LHPs) have come up as a potential candidate to meet these challenging needs [3].

Originally known as an antigravitational heat pipe (AGHP), the LHP is a highly efficient two-phase heat transfer device that operates passively on the basis of a capillary driven loop scheme. It utilizes capillary pressure developed by the fine pore wick to circulate the working fluid, and the latent heat of vaporization and condensation of the working fluid to acquire and transport heat loads. LHPs possess all the advantages of the conventional heat pipe and additionally provide reliable operation over long distance at any orientation in the gravity field. At present, LHPs with different architectures and performance capabilities are widely used in space applications [4].

Various aspects of the theory and principle of LHPs have been examined in detail [5] in the past. Most of this research is concentrated on the LHPs with large size cylindrical evaporators, 12 to $30 \mathrm{~mm}$ in diameter, for space applications. In order to employ LHPs for cooling of compact electronic equipments like 
notebooks, their potential in the direction of miniaturization has to be evaluated. By now different prototypes of the miniature loop heat pipe (mLHP) have been created and tested for cooling of power saturated electronics [6]. Usually, the design configuration of these mLHPs consisted of cylindrical evaporator with ammonia as working fluid. Pastukhov et al. [7] developed different designs of cylindrical evaporator mLHP with a nominal capacity of 25-30 W and a heat transfer distance up to $250 \mathrm{~mm}$ for cooling the CPU of a mobile PC. Under air cooling the total thermal resistance (interface to ambient) of such a system lies in the range between 1.7 and $4.0^{\circ} \mathrm{C} / \mathrm{W}$ with the mLHP own thermal resistance of 0.3 to $1.2{ }^{\circ} \mathrm{C} / \mathrm{W}$. An ammonia charged mLHP was also tested [8] for low power management and temperature control for electronic components especially for spacecraft applications.

Apart from the cylindrical design, the flat shape is another design option for the LHP evaporator. Flat evaporators can be considered as the optimum design from the point of view that they do not need any special thermal interface (saddle), i.e., cylinder-plane reducer to provide a thermal contact with the heat load source. In case of cylindrical evaporators, such a saddle creates an additional thermal resistance and increase the LHP total mass [6]. Also, flat evaporators can be easily integrated into the compact space inside the object to be cooled (e.g., notebook). By now, various investigative prototype of mLHP with flat evaporators and ammonia-stainless steel configuration have also been developed for space as well as ground based applications. Boo and Chung [9] demonstrated a successful working of a mLHP with a flat evaporator, $40 \times 50 \mathrm{~mm}^{2}$ active area and $30-\mathrm{mm}$ thickness, using a polypropylene wick. With ammonia as the working fluid the designed mLHP showed a maximum heat load of $87 \mathrm{~W}$ and thermal resistance of $0.65{ }^{\circ} \mathrm{C} / \mathrm{W}$ in the horizontal position. Another prototype of ammonia mLHP [10] was developed with flat rectangular evaporator of $5.5-\mathrm{mm}$ thickness and heat transfer length of $75 \mathrm{~mm}$. The maximum heat load with air blowing was $30 \mathrm{~W}$ and the total thermal resistance "evaporator-air" was $2{ }^{\circ} \mathrm{C} / \mathrm{W}$. Delil et al. [11] report development of a mLHP having a flat disk shaped evaporator with 44-mm diameter and 22-mm thickness. Using nickel wick and ethanol as the working fluid, the device was able to transfer a maximum thermal load of $120 \mathrm{~W}$ with a thermal resistance in the range of 0.62 to $1.32{ }^{\circ} \mathrm{C} / \mathrm{W}$ at different orientations in the gravity field.

So far, most of the mLHP prototypes have been focused on the thermal control of electronics in space. Under such circumstances, a low temperature working fluid like ammonia and a durable material like stainless steel for the loop container are the best options. In order to exploit the potential of the mLHP in ground based electronic cooling including personal and mobile computers, certain safety measures have to be observed that restrict the use of high pressure, toxic or inflammable working fluids like ammonia, acetone or different grades of alcohol. In this regard, water can be considered as the ideal working fluid. Water is the best low temperature working fluid with efficient heat transfer characteristics, presents no hazard to people, and is fully compatible with high thermal conductive material like copper. For ground based electronic cooling, the copper and water combination is considered very competitive and is widely used in conventional heat pipes for this purpose. Kim et al. [12] developed a high performance remote heat exchanger (RHE) from a copper-water heat pipe that was able to transfer 75 -W heat load dissipated by a desktop CPU of $35 \times 35 \mathrm{~mm}^{2}$ area. Moon et al. [13] built and performed test on a copper based miniature heat pipe, 2-mm thick, with woven wire wick and water as the working fluid. The miniature heat pipe device was able to effectively manage the heat load of $11.5 \mathrm{~W}$ from a $35 \times 35 \mathrm{~mm}^{2}$ laptop CPU. Water due to its excellent heat transfer characteristics like high latent heat, high surface tension and easy of availability in pure state is a widely used heat pipe working fluid in the computer cooling applications. Various copper-water based thermal designs using heat pipe or vapor chamber has made it possible to extend and maximize the cooling capability of the heat sinks for electronic applications [14]. However, it is expected that the convectional heat pipe design will not be able to provide reliable thermal control for the next generation high-end computers with extensive processing capabilities. This has instigated the need to focus on the alternative and efficient thermal designs using mLHPs. Miniature LHPs with copper-water arrangement can serve as potential replacements of conventional heat pipes in electronic cooling applications.

Although the copper-water combination is not yet fully explored in mLHPs, some of the investigative prototypes which have been developed with this combination have shown superior performance and high heat manageable potential. In their work on mLHPs, Maydanik et al. [15] developed and tested different prototypes of ammonia-stainless steel and copper-water mLHPs with cylindrical evaporators, 5 and $6 \mathrm{~mm}$ in diameter, and heat transfer distances up to $300 \mathrm{~mm}$. Tests have shown that a nominal heat load of $70 \mathrm{~W}$ for ammonia mLHP and $130 \mathrm{~W}$ for water mLHP can be obtained. The work clearly pinpoints the potential of the copper-water mLHP for electronic cooling applications. Kiseev et al. [16] presented his results on the mLHP with flat evaporator, $31.8 \mathrm{~mm}$ diameter and $15-\mathrm{mm}$ thick, using different configuration of capillary structure (i.e., nickel and titanium) and working fluids (i.e., acetone and water). With water as the heat transfer agent, the device showed higher heat potential of $160 \mathrm{~W}$ while the thermal resistance was within 0.5 to $0.8{ }^{\circ} \mathrm{C} / \mathrm{W}$. It is evident from the current body of knowledge that very limited research has been done on the mLHPs with water as the working fluid. In order to utilize the unique thermal characteristics of the mLHPs for cooling compact electronics like laptop, development of these devices in this respect is very crucial.

In this study, the design, development and results of tests on a mLHP with flat evaporator geometry are presented. A flat evaporator of copper with an active diameter of $30 \mathrm{~mm}$ and characteristic thickness of $10 \mathrm{~mm}$ was developed to transport $70 \mathrm{~W}$ over a distance of up to $150 \mathrm{~mm}$. Here, a flat evaporator is preferable due to lower interface resistance and easy of integration inside the limited space of notebook PC. The device uses water as the working fluid to promote its viability for cooling portable and personal computers. Results of the experiment demonstrated satisfactory operation and thermal behavior of LHPs on a miniature scale. 


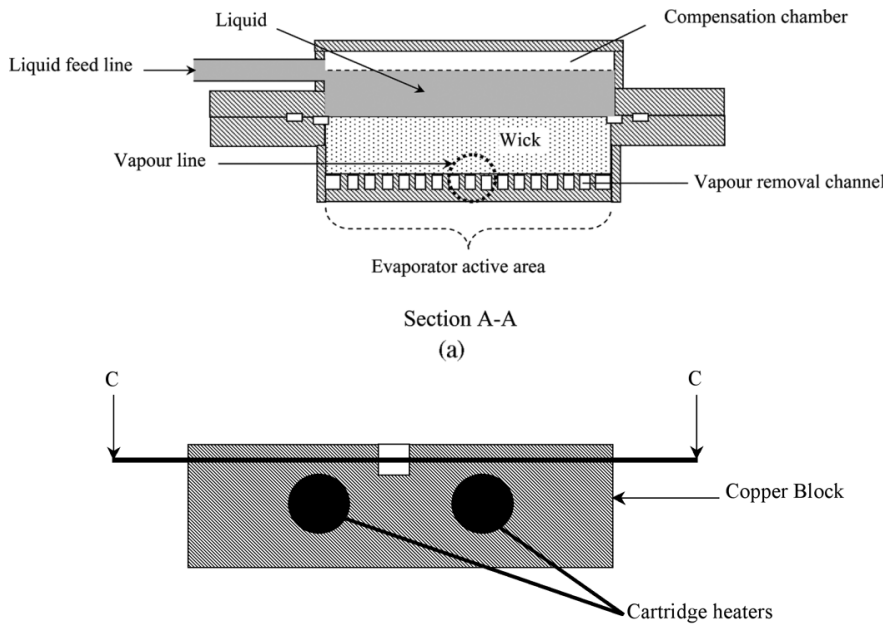

Section A-B

(b)

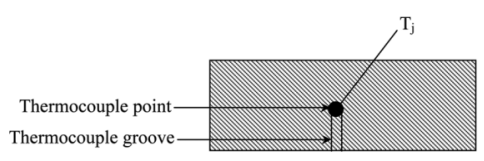

Section C-C

(c)

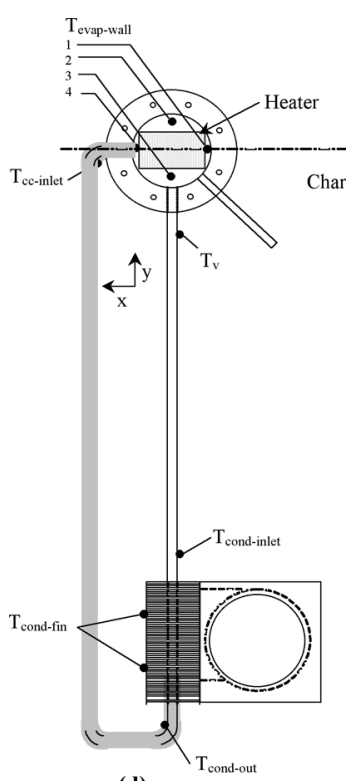

(d)

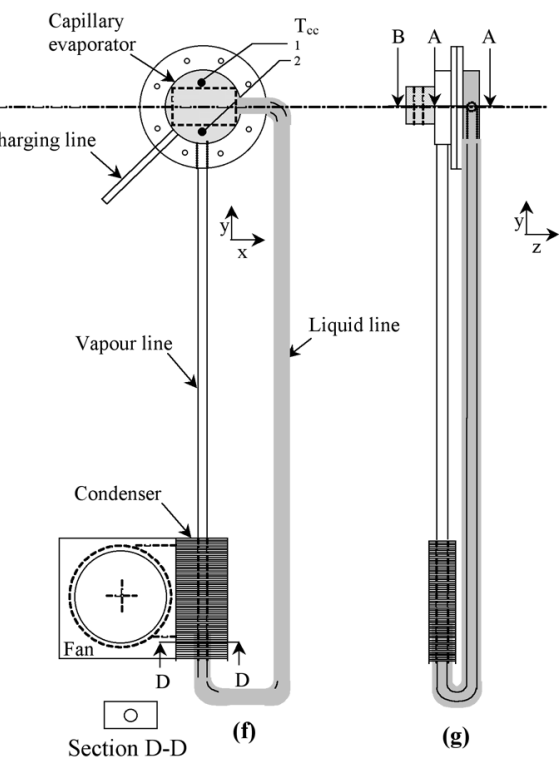

(e)
Fig. 1. Schematic of the experimental prototype and test layout for the mLHP: (a) cross-sectional details of the mLHP evaporator; (b) cross section view of the heater block showing cartridge heaters; (c) sectional view of the heater face showing position of the thermocouple groove and temperature measurement point; (d) bottom view of the mLHP showing thermocouple locations and heater position; (e) condenser cross section; (f) top view of the mLHP showing different parts; and $(\mathrm{g})$ side view of the mLHP clearly showing the heater, evaporator and compensation chamber positions.

\section{MLHP PROTOTYPE DESCRIPTION}

The design schematic of the mLHP is as shown in Fig. 1(f). It consists of a flat disk shaped evaporator with a characteristic diameter of $30 \mathrm{~mm}$ and thickness of $10 \mathrm{~mm}$. Fig. 1(a) shows
TABLE I

MAIN DESIGN PARAMETERS OF THE mLHP

\begin{tabular}{|l|l|}
\hline Parameter & Value \\
\hline Evaporator Shape & Flat Disk Shaped \\
\hline Evaporator heating face area, $\mathrm{cm}^{2}$ & 7.1 \\
\hline Heat Load simulator area (heater size), $\mathrm{cm}^{2}$ & 3.75 \\
\hline Body Material & Copper \\
\hline Wick Material & Nickel \\
\hline Wick Effective Pore radius, $\mu \mathrm{m}$ & $3-5$ \\
\hline Vapour Line Length, $\mathrm{mm}$ & 150 \\
\hline Liquid Line Length, $\mathrm{mm}$ & 290 \\
\hline Vapour \& Liquid Line Diameter (Internal/External), $\mathrm{mm}$ & $2 / 3$ \\
\hline Condenser Type & External Fins \\
\hline Condenser Length, $\mathrm{mm}$ & 50 \\
\hline Condenser Fin Surface Area, $\mathrm{cm}^{2}$ & 200 \\
\hline Working Fluid & Water \\
\hline & \\
\hline
\end{tabular}

the cross-sectional view of the evaporator. The thickness of the mLHP evaporator also incorporates the compensation chamber which is connected to the evaporator through the wick structure. The function of the compensation chamber is to accommodate the excess liquid inventory displaced from evaporator grooves, vapor line and condenser during startup. Apart from this, the compensation chamber also provides the wick structure with direct access to the liquid and thus promotes its wetting at all the times. The compensation chamber design has to take into consideration the total volume of the loop so that it can accommodate most of the liquid inventory present in the loop. The flat diametric face of the evaporator was used as the active heating area and provides direct connection with the heat load simulator without need of any cylinder-to-plane reducer material (i.e., saddle) at the interface. An efficient system of vapor removal channel was formed on the inner face of the heating zone by machining 15 grooves with rectangular cross-section of 1 -mm depth and $0.5-\mathrm{mm}$ width. Nickel wick of 3-mm thickness with $3-5-\mu \mathrm{m}$ mean pore radius and $75 \%$ porous volume provided sufficient capillary pressure for continuous circulation of the working fluid around the loop during operation at different heat loads. Apart from providing capillary pumping, the wick structure also functions as a thermal and hydraulic lock to inhibit back conduction of heat and prevent any back flow of vapor from the evaporation zone to the compensation chamber. The vapor lock is provided by the presence of the liquid in the fine pores of the capillary structure while heat leaks to the compensation chamber can be decrease by using low conductive capillary structure. Within the framework of the proposed design, nickel serves as an optimum choice to achieve these functionalities due to its low thermal conductivity and capability to be sintered in smaller pore sizes with relatively high porosity. The body and the transport lines of the mLHP were made of copper.

The condenser of the mLHP was provided with external fins [Fig. 1(e)] measuring $20 \times 10 \mathrm{~mm}$ with a thickness of $0.2 \mathrm{~mm}$. Table I gives the main design parameters of the mLHP. Water was used as the heat transfer fluid that ensured excellent heat transfer characteristics in the temperature range between 50 to $100{ }^{\circ} \mathrm{C}$. The charging volume of the water was decided on the basis of the volume of the liquid line, compensation chamber and porous volume of the wick. In the cold state, at least $50 \%$ of the compensation chamber should be filled with liquid for the proper wetting of the wick and reliable startup of the loop. 


\section{TESTING MethoD}

The thermal performance of the mLHP was tested by using a heater of $3.75 \mathrm{~cm}^{2}$ area. In this case, the active area of the evaporator, i.e. the surface where capillary structure makes contact with the evaporator wall and there are vapor removal channels, is more than the active thermal footprint of the heater face. As a result, the current testing provides a condition of nonuniform heating to the evaporator active face. Here, nonuniform heating was done on approximately $3 / 5$ of the active zone area. The heat load simulator [Fig. 1(b))] was in the form of copper block embedded with two cylindrical cartridge heaters. During testing, the heater block was attached symmetrically to the center of the circular heat absorbing face of the mLHP evaporator [Fig. 1(d) and $(\mathrm{g})]$.

The condenser cooling was accomplished by forced convection provided by an air cooling fan using ambient air with an inlet temperature of $24 \pm 2{ }^{\circ} \mathrm{C}$. The temperature was measured at different points on the mLHP using K-Type thermocouples with an accuracy of $\pm 0.1{ }^{\circ} \mathrm{C}$. Fig. 1(c), (d), and (f) shows the experimental set up for testing the mLHP along with the location of the thermocouples. Data from these thermocouples was acquired every 10 s by a "Keyence Thermo Pro 3000" based data acquisition system. The thermal performance of the mLHP was measured on the basis of the evaporator temperature, maximum heat capacity, evaporator thermal resistance, $\mathrm{mLHP} / \mathrm{heat}$ pipe thermal resistance and total thermal resistance of the device. The following relations (1-3) were used to calculate the thermal resistances.

Evaporator thermal resistance

$$
R_{e}=\frac{\left(T_{e}-T_{v}\right)}{\dot{Q}} .
$$

Heat Pipe thermal resistance

$$
R_{h p}=\frac{\left(T_{e}-T_{c}\right)}{\dot{Q}} .
$$

Total thermal resistance

$$
R_{t}=\frac{\left(T_{j}-T_{a}\right)}{\dot{Q}} .
$$

Calculation for the overall heat transfer coefficient of the evaporator was made by using

$$
h_{e}=\frac{\dot{Q}}{A_{e}\left(T_{e}-T_{v}\right)} .
$$

In the above equations, $T_{e}$ is the external temperature of the evaporator active zone which was measured by averaging the temperatures of the thermocouples fixed on the evaporator heating face $\left(T_{\text {evap-wall }} 1,2,3,4\right)$. The vapor temperature $T_{v}$ was taken to be equal to the temperature at the evaporator outlet as indicated in the Fig. 1(d). Temperature of the external condenser surface $\left(T_{c}\right)$ was calculated by taking mean of the readouts from the thermocouples installed at the condenser inlet $\left(T_{\text {cond-inlet }}\right)$, condenser finned surface $\left(T_{\text {cond-fin }}\right)$ and condenser outlet $\left(T_{\text {cond-out }}\right)$. For measuring the temperature at the junction $\left(T_{j}\right)$ of the mLHP evaporator and heat simulator, a special groove [Fig. 1(c)] was made at the center of the heating face of simulator block in which the thermocouple point was fixed using thermally conductive epoxy resin.

A digital wattmeter with an error of $\pm 0.1 \mathrm{~W}$ was used to measure and control the input heat load to the heat simulator. During the experiment the input power to the heat simulator was increased in steps of $5 \mathrm{~W}$. The error in determining the thermal resistance- $R$ is formed from an estimation of the measurement errors of the input heat load $(\stackrel{\bullet}{Q})$ and temperature measurements. It should be noted that the error of estimation will be larger at the low heat loads due to the higher values of the associated thermal resistances at such loads. Uncertainties in the reported thermal resistances were carried out over the entire range of applied heat load in the experiment and lie between $1.26 \%$ to $6.23 \%$. Similarly in the determination of the evaporator heat transfer coefficient $-h_{e}$, (from temperatures and heat load measurements) uncertainties were estimated to be within $3.50 \%$ to $9.04 \%$, respectively. Heat losses due to the natural convection and radiation heat transfer from the outer surface of the heat load simulator and the mLHP evaporator was found to be the functions of the temperature difference of the hot surface and the ambient air. In the present test, the heat losses were estimated [17] to be about $6 \%$ to $8 \%$ of the input power.

Testing of the mLHP prototype was done in the horizontal configuration with the evaporator and condenser at the same level. Startup of the mLHP was assumed to occur with the rise in temperature of the entire vapor line and consequently clearing of liquid from the vapor line. For a successful startup at a given heat load the temperature difference between the outlet of evaporator and inlet of condenser should be less than or equal to $1^{\circ} \mathrm{C}$. At a given heat load, steady state was characterized by the constant evaporator temperature.

\section{TEST RESUlt AND Discussion}

As heat load is applied to the evaporator active zone, the temperature of the evaporator rises and results in the vaporization of the working fluid. The resulting vapor pushes the liquid from the grooves and vapor line. Evaporating meniscus is formed at the wick-wall interface of the capillary structure inside the evaporation zone which is responsible for developing the capillary pressure to circulate the working fluid around the loop. This is followed by a rise in temperature of evaporator outlet and then condenser inlet which registers the startup of the LHP. The excess liquid cleared from the evaporator grooves and vapor line by the vapor is displaced to the compensation chamber. In Fig. 1(d), (f), and (g) the shaded parts of the mLHP shows the portion occupied by the liquid while the blank portion is filled with vapor.

Fig. 2(a) shows the startup process with $20-\mathrm{W}$ input power. The device showed reliable startup under low as well as high heat loads and achieved steady state under every step (5 W) increase in input load. Fig. 2(b) shows startup of the device from the cold state under 50-W heat load. The capillary evaporator does not show any symptoms of wick depriming like overshoot of evaporator temperature or back vapor flow from evaporator to compensation chamber for high heat loads or abrupt power down conditions.

Fig. 3 gives the heat load dependence of the evaporator surface temperature. The plot clearly shows that the LHP is able to 


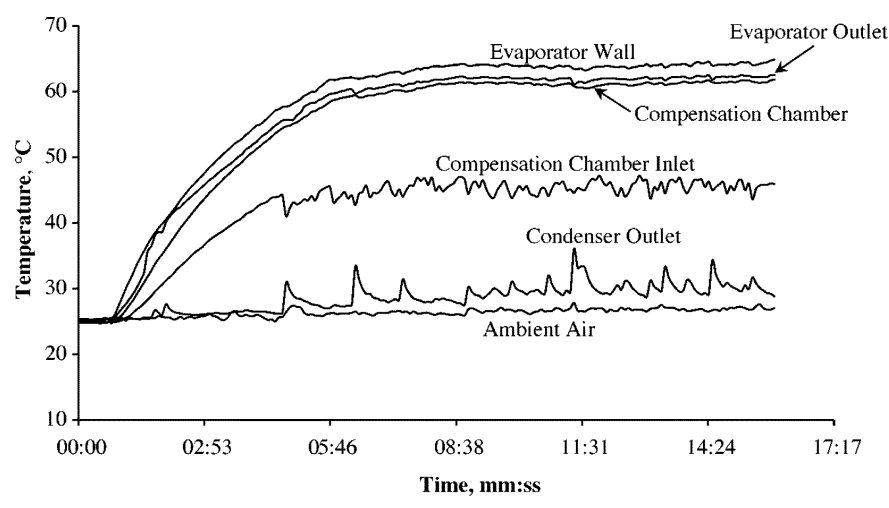

(a)

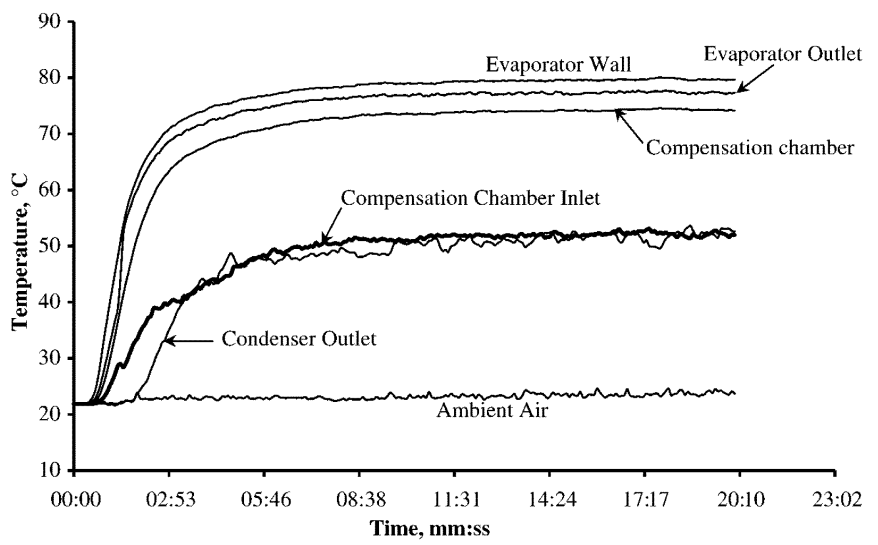

(b)

Fig. 2. mLHP startup test under different heat loads: (a) low heat load, Power $=20 \mathrm{~W}$ and $(\mathrm{b})$ high heat load, Power $=50 \mathrm{~W}$.

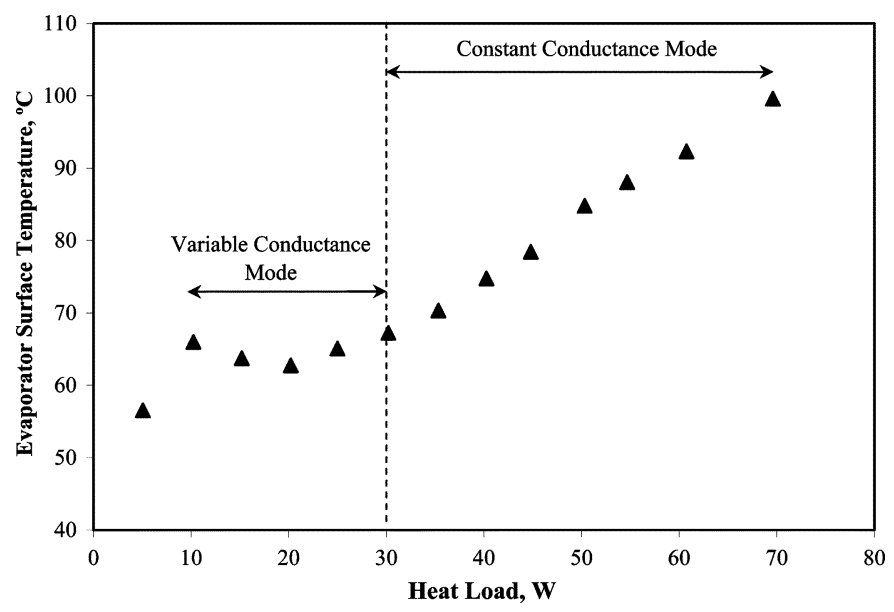

Fig. 3. Head load dependence of the evaporator temperature showing different modes of conductance of mLHP.

automatically regulate its mode of operation with the changing heat load. For input power less than $30 \mathrm{~W}$, variable conductance mode is observed. In this case one can observe that different heat loads may correspond to the same value of temperature. At low heat loads, the mass flow rate of the working fluid is small therefore the compensation chamber and the condenser are partially filled with the liquid. The temperature of the compensation chamber which dictates the saturation condition inside the evaporator is decided by the outcome of two main factors. The first one is the amount of the parasitic heat flow from evaporator to the compensation chamber via the capillary structure and the evaporator wall and the second is the liquid redistribution between the condenser and the compensation chamber which take place under changes of head load. With the increase in heat load, the effect of these competitive processes, i.e., heat inflow and liquid displaced to the compensation chamber also increase. As a result of this, the compensation chamber and thus evaporator wall temperature is stabilized to some extent and helps LHP to auto-regulate the source temperature. The variable conductance mode of LHP continues to the stage until the compensation chamber is completely filled with liquid and the entire condensation surface is utilized for heat removal. For a heat load of more than $30-\mathrm{W}$, a constant conductance mode is realized in which the condensation surface is fixed, as presented by Fig. 3. In this mode, LHP behaves like a conventional heat pipe and shows a monotonic temperature trend with the changing heat load.

The maximum heat capacity of the mLHP in electronics cooling is mainly decided by the maximum permissible temperature at the heat source which is normally regarded as $100{ }^{\circ} \mathrm{C}$. In case of the designed mLHP, it was able to transfer a $70-\mathrm{W}$ maximum heat load while maintaining the temperature of the evaporator within $100 \pm 1{ }^{\circ} \mathrm{C}$ limit. The nominal capacity of the $\mathrm{mLHP}$ is the heat load at which the evaporator temperature reaches $80 \pm 1{ }^{\circ} \mathrm{C}$ and in this case was $45 \mathrm{~W}$. It is evident from the large values for the maximal and nominal capacities that the designed mLHP can handle high heat fluxes as well as conditions of the nonuniform heating without any performance issues. This is attributed to the efficient heat exchange in the evaporation zone of the mLHP evaporator in which the evaporating menisci is present very close to the heated wall. For the current mLHP prototype, effective heat transfer coefficient in the evaporator reaches maximum value of $22600 \mathrm{~W} / \mathrm{m}^{2 \circ} \mathrm{C}$. The plot in Fig. 4 clearly indicates that high values of the heat transfer coefficient in the evaporator were achieved in the entire range of the applied heat loads. It should be noted that the maximum value of the heat transfer coefficient specified above is limited by the operating temperature limit. During the entire range of heat load, there was not any indication of heat transfer crisis phenomenon inside the evaporator.

In the LHPs, there also exists some minimum value of the startup heat load. To start and maintain the working fluid circulation in the loop, a minimum pressure difference is required between the evaporating and absorbing surface of the wick. This pressure difference is required for displacing the liquid from the vapor line and filling the liquid line and compensation chamber. Owing to the heat flow through the wetted metal wick and high conductive evaporator wall, part of the heat applied to the evaporator active zone leaks to the compensation chamber. In addition to this, for the successful startup of the mLHP from a pre startup situation in which the evaporator grooves are flooded with the liquid, certain degree of superheat has to be provided to the liquid present inside the grooves to initiate boiling and eventually clearing of the grooves and vapor line of the liquid. At low power inputs, due to the heat loss to the compensation chamber and ambient, the device is not able to instigate the startup phenomena from the available power. 


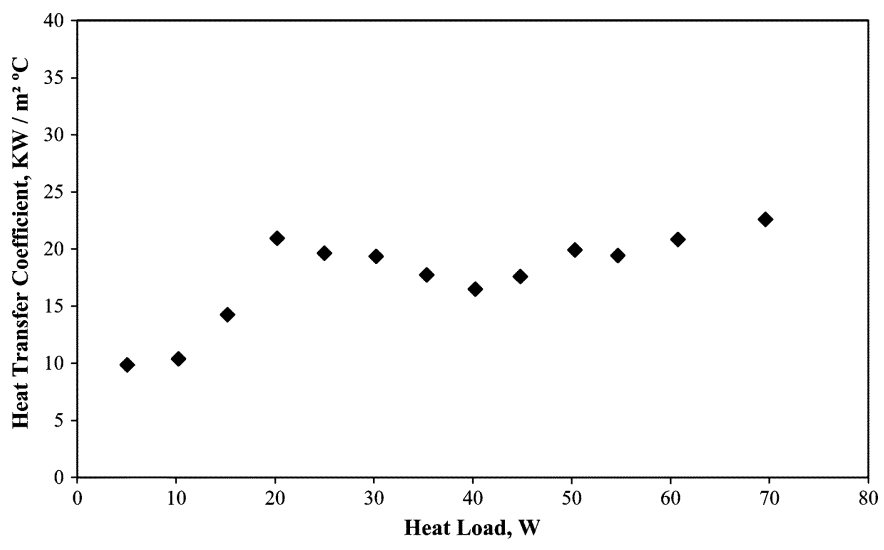

Fig. 4. Evaporator heat transfer coefficient versus heat load.

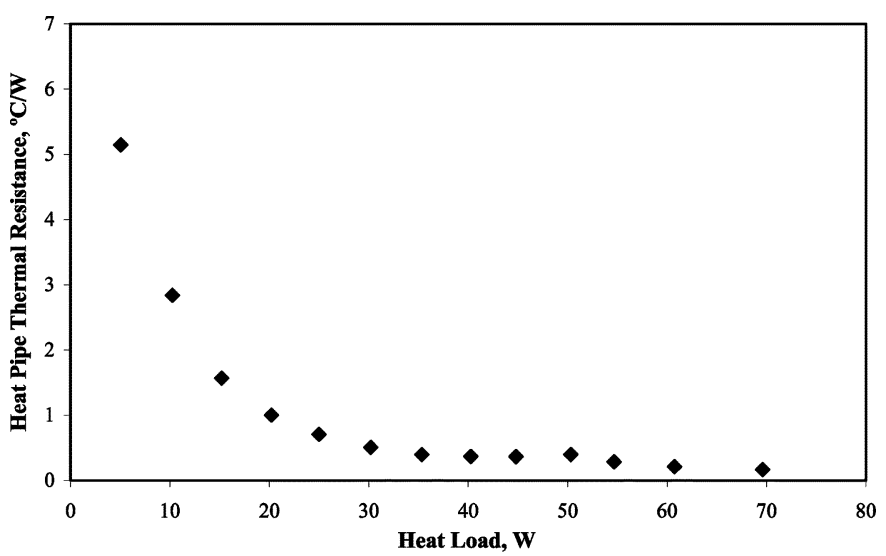

Fig. 5. mLHP (evaporator to condenser) thermal resistance versus heat load.

In the present mLHP prototype, as high conductive material copper was used in the evaporator body with the low thermal conductive nickel wick. This approach provides twofold advantages by intensifying the heat exchange in the evaporation zone and reducing the parasitic heat flows through the wick into the compensation chamber. The mLHP device was able to startup successfully for as low as 5-W heat load. However, it was noted that thermal resistance of the mLHP was very high for heat load below $10 \mathrm{~W}$. This is because at low heat loads bulk quantity of the fluid is present in part of condenser and liquid line and therefore the compensation chamber is devoid of adequate liquid quantity. As discussed before, evaporator temperature is directly affected by the compensation chamber conditions, this result in the high operating temperatures at low heat loads, which is evident from the Fig. 3.

In the Fig. 5 the steady decrease in the heat pipe thermal resistance, $R_{\mathrm{hp}}$ (evaporator surface to condenser surface) can be observed as input power increases. This is due to the combined effect of increase in the Merit number of the water at higher temperature and adequate supply of the liquid to the wick structure and compensation chamber with the increase in heat load. In the context of heat transfer, Merit number $(M)$ is defined as ratio of the product of liquid density $\rho_{l}$, liquid surface tension $\sigma_{l}$, and latent heat $L$ to the liquid viscosity $\mu_{l}$

$$
M=\frac{\rho_{l} \sigma_{l} L}{\mu_{l}} .
$$

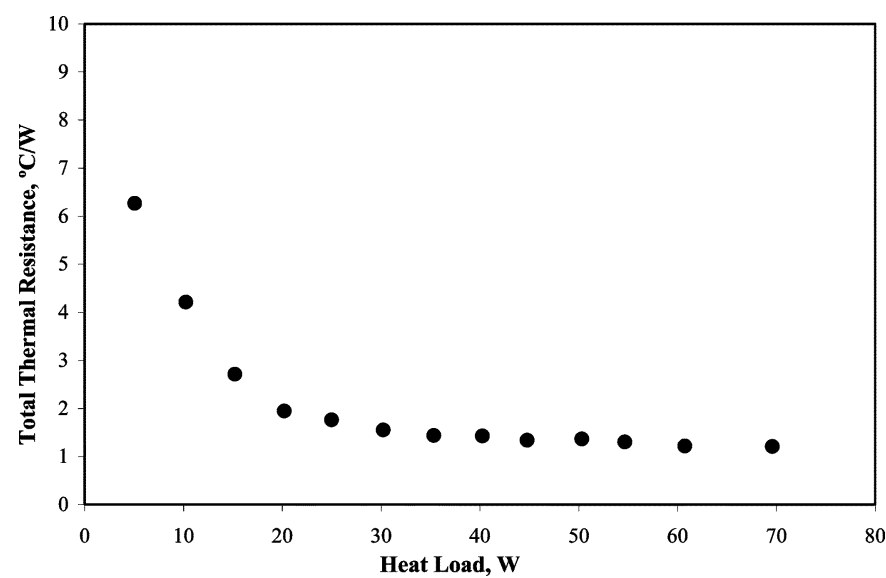

Fig. 6. mLHP total thermal resistance versus heat load.

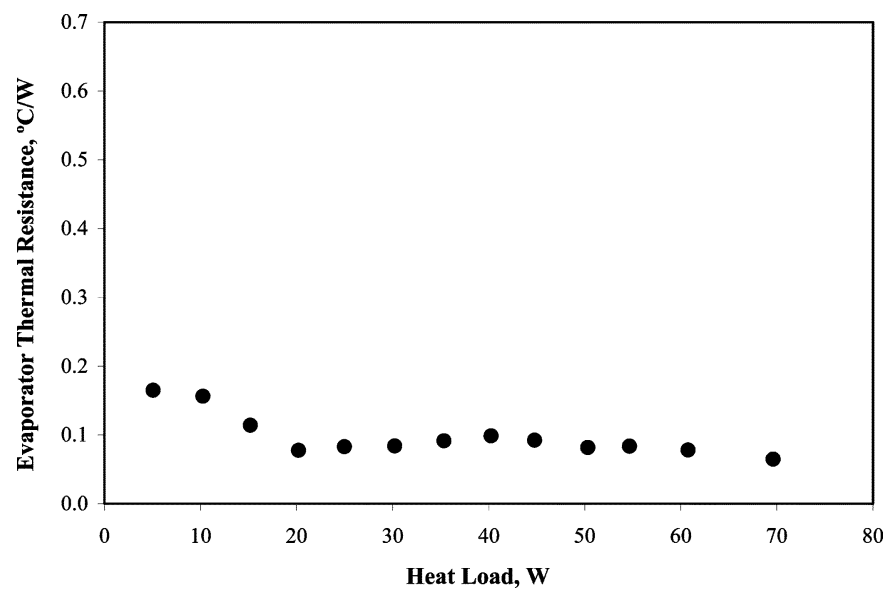

Fig. 7. mLHP evaporator thermal resistance versus heat load.

Merit number is a mean of ranking heat pipe working fluids such that fluids with the higher Merit number are more desirable. Water is considered as a superior working fluid for operation [18] in the temperature range of 350-500 K where the alternative organic fluids tend to have considerably low Merit numbers. As the operating temperature of the device using water increases, its Merit number is improved. On the other hand, at higher temperatures the vapor density and vapor pressure of water increase which tend to decrease the vapor pressure losses in the vapor line and evaporator grooves. It is an outcome of the above phenomena that the thermal performance of the device is improved at higher heat loads. Apart from this, with the increase in applied heat load to the mLHP evaporator, the quantity of the liquid inventory inside the compensation chamber and flow rate of the liquid inside the loop increases that reduces the effect of heat leaks from the evaporator to the compensation chamber and thus further reduces the thermal resistance of the device.

The minimum value of the heat pipe thermal resistance- $-R_{\mathrm{hp}}$ is $0.17^{\circ} \mathrm{C} / \mathrm{W}$ at the capacity of $70 \mathrm{~W}$ and an evaporator temperature of $99.6^{\circ} \mathrm{C}$. For the total thermal resistance $-R_{t}$, heat load dependence of which is presented in Fig. 6, the minimum value of $1.2^{\circ} \mathrm{C} / \mathrm{W}$ was observed at $70 \mathrm{~W}$. The evaporator is the most critical component of the LHP and decides the overall performance of the device. The efficiency of the heat transfer process 
in the evaporation zone of the LHP is measured on the basis of the evaporator thermal resistance- $R_{e}$ which is the resistance presented to the heat flow from the evaporator active zone to the vapor inside the evaporation zone. Fig. 7 presents the plot for evaporator thermal resistance versus heat load. Due to very low spreading and low conductive resistance offered by the evaporator active zone that was made from copper, very low values of $R_{e}$ were obtained in the mLHP evaporator, with the minimum value of $0.06{ }^{\circ} \mathrm{C} / \mathrm{W}$ at $70 \mathrm{~W}$. The thermal resistance from condenser to ambient contributes to $0.8 \pm 0.2{ }^{\circ} \mathrm{C} / \mathrm{W}$ and proved to be the main component of the total thermal resistance- $R_{t}$.

\section{CONCLUSION}

The results of the paper can be summarized as follows.

- A mLHP with flat disk shaped evaporator, $30 \mathrm{~mm}$ in diameter and $10 \mathrm{~mm}$ thickness, and heat transfer length of $150 \mathrm{~mm}$ was developed. The device was made from copper with water as the working fluid.

- Using forced air cooling of the condenser with ambient air at a temperature of $24 \pm 2{ }^{\circ} \mathrm{C}$, the mLHP was able to transfer maximum heat load of $70 \mathrm{~W}$. For mLHPs own thermal resistance (evaporator surface to condenser surface), a minimum value of $0.17{ }^{\circ} \mathrm{C} / \mathrm{W}$ was achieved at $70 \mathrm{~W}$ with evaporator temperature of $99.6{ }^{\circ} \mathrm{C}$, and the corresponding total thermal resistance, $R_{t}$ (heater to ambient air) in this case was $1.2^{\circ} \mathrm{C} / \mathrm{W}$.

- With the use of high conductive material, i.e., copper for the mLHP evaporator and an efficient system of vapor removal channel in the evaporation zone, it was possible to achieve evaporator thermal resistance as low as $0.06^{\circ} \mathrm{C} / \mathrm{W}$ while maximum value for heat transfer coefficient in the evaporator reaches $22600 \mathrm{~W} / \mathrm{m}^{2 \circ} \mathrm{C}$. Also, flat evaporators provide easy interfacing to the heat source without need of any cylinder-to-plane reducer saddle for attachment, which creates additional thermal resistance in the case of cylindrical evaporators.

- Water served as an efficient working fluid in the mLHP and showed superior heat transfer characteristics over the entire range of input power. Also, for the suggested application, water presents no hazard to be used in environments where people are present.

- mLHP has proven to be very versatile and promising device for thermal control of electronics devices including personal computers and notebooks.

\section{ACKNOWLEDGMENT}

The authors would like to thank Dr. Y. Saito, Dr. T. Nguyen, and V. Wuttijumnong, Fujikura, Ltd., Japan, for their help and support throughout the project.

\section{REFERENCES}

[1] M. Mochizuki, Y. Saito, T. Nguyen, V. Wuttijumnong, X. Wu, and T. Nguyen, "Revolution in fan heat sink cooling technology to extend and maximize air cooling for high performance processors in laptop/ desktop/server application," in Proc. IPACK'05, San Francisco, CA, Jul. 17-22, 2005, [CD ROM].
[2] I. Saucius, R. Prasher, J. Chang, H. Erturk, G. Chrysler, C. Chiu, and R. Mahajan, "Thermal performance and key challenges for future CPU cooling technologies," in Proc. IPACK'05, San Francisco, CA, Jul. 17-22, 2005, [CD ROM].

[3] Y. F. Maydanik, "State-of-the-art of CPL and LHP technology," in Proc. 11th Int. Heat Pipe Conf., Tokyo, Japan, Sep. 12-16, 1999, pp. 19-30.

[4] T. D. Swanson, "Thermal control technologies for complex spacecraft," in Proc. 13th Int. Heat Pipe Conf., Shanghai, China, Sep. 21-25, 2004, pp. 1-11.

[5] Y. F. Maidanik and Y. G. Fershtater, "Theoretical basis and classification of loop heat pipes and capillary pumped loops," in Proc. 10th Int. Heat Pipe Conf., Stuttgart, Germany, Sep. 21-25, 1997, [CD ROM].

[6] Y. F. Maydanik, "Miniature loop heat pipes," in Proc. 13th Int. Heat Pipe Conf., Shanghai, China, Sep. 21-25, 2004, pp. 24-37.

[7] V. G. Pastukhov, Y. F. Maydanik, and M. A. Chernyshova, "Development and investigation of miniature loop heat pipes," in Proc. 29th Int. Conf. Environ. Syst., Denver, CO, 1999 [Online]. Available: http:// www.sae.org/technical/papers/1999-01-1983

[8] W. B. Bienert, W. J. Krotiuk, and M. N. Nikitkin, "Thermal control with low power miniature loop heat pipes," in Proc. 29th Int. Conf. Environ. Syst., Denver, CO, 1999 [Online]. Available: http://www.sae. org/technical/papers/1999-01-2008

[9] J. H. Boo and W. B. Chung, "Thermal performance of a loop heat pipe having propylene wick in a flat evaporator," in Proc. HT'05 Conf., San Francisco, CA, Jul. 2005, [CD ROM].

[10] V. G. Pastukhov, Y. F. Maydanik, and S. V. Vershinin, "Miniature loop heat pipes for electronic cooling," Appl. Therm. Eng., vol. 23, pp. $1125-1135,2003$.

[11] A. A. M. Delil, V. Baturkin, Y. Fridrichson, Y. Khmelev, and S. Zhuk, "Experimental results of heat transfer phenomena in a miniature loop heat pipe with a flat evaporator," in Proc. 12th Int. Heat Pipe Conf., Moscow, Russia, May 19-24, 2002, pp. 126-133.

[12] K. W. Kim, M. H. Won, J. W. Kim, and B. J. Back, "Heat pipe cooling technology for desktop PC CPU," Appl. Therm. Eng., vol. 23, pp. 1137-1144, 2003.

[13] S. H. Moon, G. Hwang, H. G. Yun, T. G. Choy, and Y. II. Kang, "Improving thermal performance of miniature heat pipe for notebook PC cooling," Microelectron. Rel., vol. 42, pp. 135-140, 2002.

[14] M. Mochizuki, T. Nguyen, K. Mashiko, Y. Saito, T. Nguyen, V. Wuttijumnong, and $\mathrm{X}$. Wu, "Practical application of heat pipe and vapor chamber for cooling high performance personal computer," in Proc. 13th Int. Heat Pipe Conf., Sep. 21-25, 2004, pp. 23-30.

[15] Y. F. Maydanik, S. V. Vershinin, M. A. Korukov, and J. M. Ochterbeck., "Miniature loop heat pipes-a promising means for cooling electronics," IEEE Trans. Compon. Packag. Technol., vol. 28, no. 2, pp. 290-296, Jun. 2005.

[16] V. M. Kiseev, A. S. Nepomnyashy, N. L. Gruzdova, and K. S. Kim, "Miniature loop heat pipes for CPU cooling," in Proc. 7th Int. Heat Pipe Symp., Jeju, Korea, Oct. 12-15, 2003, [CD ROM].

[17] Y. A. Cengel and R. H. Turner, Fundamentals of Thermal-Fluid Sciences. New York: McGraw Hill, 2001.

[18] P. D. Dunn and D. A. Reay, Heat Pipes. New York: Pergamon, 1994.

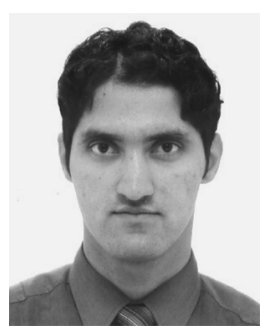

Randeep Singh received the B.E. degree in mechanical engineering from Punjab Technical University, Jalandhar, India, in 2002 and is currently pursuing the Ph.D. degree in thermal control of high-powered microprocessors at the Royal Melbourne Institute of Technology (RMIT), Victoria, Australia.

$\mathrm{He}$ has been a Research Associate at RMIT since 2003. While working on his doctorate, he has been actively involved with various projects on two phase and single phase cooling of computer microprocessors in collaboration with Fujikura, Ltd., Tokyo, Japan. He is an author of over 10 research papers published in referred international conferences related to the heat pipe technology. His research interests include LHPs, capillary pumped loops, single phase heat transfer, and porous structures.

Mr. Singh received the RMIT Postgraduate Research Award of the Year for the Best Published Paper in 2005. He is an Associate Member of the International Institute of Refrigeration (France) since 2002. 


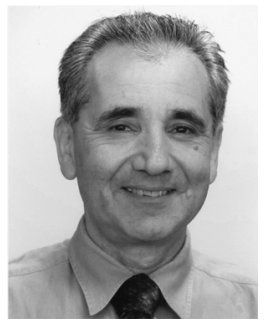

Aliakbar Akbarzadeh received the B.S. degree from the University of Tehran, Tehran, Iran, in 1966 and the M.S. and Ph.D. degrees from the University of Wyoming, Laramie, in 1972 and 1975, respectively.

$\mathrm{He}$ is a Professor in mechanical engineering in the Royal Melbourne Institute of Technology, Victoria, Australia, where he is also the leader of Energy Conservation and Renewable Energy Research Group. He is the author/co-author of more than 75 scientific papers and two books concerned with his research and development in the field of energy conservation and renewable energy.

Dr. Akbarzadeh received the 1994 Best Paper Award from ASME for his work on solar pond technology, the Australian Government's 1996 National Energy Award, and the 1998 Business and Higher Education Round Table Award in Victoria for the development of innovative technologies for industrial waste heat recovery systems. He is a Fellow of the Institution of Engineers, Australia, and served as the Chairman of the 1996 International Symposium on Heat Pipes and 1995 International Symposium on Energy, Environment and Economics.

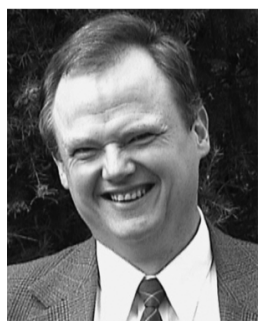

Chris Dixon received the B.Eng. and M.Eng. degrees in mechanical engineering from the University of Melbourne, Victoria, Australia, in 1975 and 1979, respectively. His master's research work involved the practical study of a novel solar boosted heat pump.

Results from this machine were sufficiently encouraging to attract funding from government and industry for further development of various applications of this technology. This activity culminated in the commercial production and marketing, in Australia and abroad, of a domestic hot water solar boosted heat pump. $\mathrm{He}$ has authored/co-authored more than 20 peer reviewed conference papers and is the joint inventor of two patents. He has an ongoing research interest in thermodynamic design and has been involved in numerous research and consulting activities related to heat pumps, refrigeration, air conditioning, solar energy and energy conservation, both before and after he joined Royal Melbourne Institute of Technology (RMIT), Victoria, Australia, in 1992.

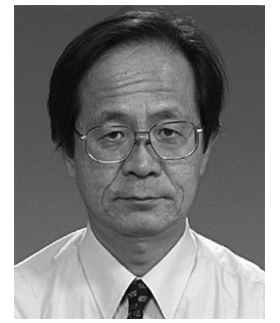

Mastaka Mochizuki received the M.S. degree in mechanical engineering from Numazu National College of Technology, Shizuoka, Japan, in 1972 and the Ph.D. degree in thermal engineering from Kumamoto University, Kunamoto City, Japan, in 2002.

$\mathrm{He}$ is a General Manager in the Research and Development Department, Thermal Division, Fujikura, Ltd., Tokyo, Japan, which he joined in 1972. He is an author/co-author of over 150 referred journal/conference papers, 300 patents, and three books related to the heat transfer technology. His research focus is in the area of heat pipes, two-phase heat transfer, and electronics cooling.

Dr. Mochizuki has served as the Deputy Chairman in the Japan Association of Heat Pipes since 1996 and as an Advisory Scientist at the University of Tokyo, Tokyo, Japan, since 2005

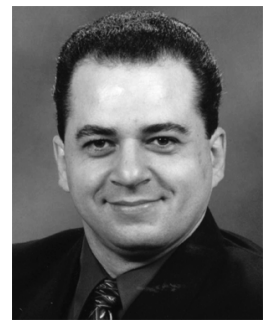

Roger R. Riehl received the B.S., M.S., and Ph.D. degrees in mechanical engineering from Sao Paulo State University, Sao Paulo, Brazil, in 1992, 1996, and 2000, respectively.

$\mathrm{He}$ is a Research Engineer at the Space Mechanics and Control Division, National Institute for Space Research (INPE), São José dos Campos, Brazil, where he joined in 2003 and is responsible for the development of the heat pipe and LHP technology for low orbit and geostationary satellites. Before joining INPE, he was a Research Associate with the Federal University of Santa Catalina, Santa Catalina, Brazil, for two years on the thermal control of scientific payload for microsatellites and/or the International Space Station using capillary pumped loops. He has over 35 publications in international conferences and indexed journals related to heat pipes, as well as several internal reports devoted to the implementation of this type of technology. 